and $11.5 \mathrm{lb}$. respectively. These improved weights are comparable to those recorded in the United States.

The difference in appearance and behaviour of the poults receiving penicillin was most striking, particularly during the first two to three weeks of life. There was a very obviously increased metabolism. Birds were more active and had much greater vitality. They consumed more food and spent less time in the heated compartment of the brooder. There was a marked difference in mortality and later, at the fifth to sixth weeks, when birds were exposed to natural infection with coccidia, the death-rate was practically nil and the growth-rate was only slightly slowed. In the control pens there was considerable mortality, and growth practically ceased for a week or more. Further experiments are in progress to confirm the latter findings.

The experiments briefly summarized show that the addition of small amounts of penicillin to the diet of growing turkeys not only produced a significant increase in growth-rate but also that it appeared to have a profound effect in stimulating metabolism, tiding chicks over a critical period of susceptibility to chilling and other non-specific causes of mortality during the first few weeks of life. It is too soon to make definite claims concerning a possible effect in increasing resistance to coccidiosis, but preliminary results are suggestive.

Rate of growth and mortality during rearing are factors of primary economic importance to the turkey industry and largely determine the profitability of the undertaking. 'The success obtained with penicillin suggests that its more general use would be highly beneficial. There may be objections to feeding it to future breeding stock; but its administration to birds destined for the table within the shortest possible time would appear to be strongly indicated.

$$
\text { J. E. WILSON }
$$

Ministry of Agriculture and Fisheries,

Veterinary Laboratory, Eskgrove,

Lasswade, Midlothian.

$$
\text { Nov. } 29 .
$$

${ }^{1}$ Stokstad, E. L. R., and Jukes, T. H., Proc. Soc. Exp. Biol., 73, 523 (1950). ${ }^{2}$ Whitehall. A: R., Oleson, J. J., and Hutchings, B. L., Proc. Soc.
Exp. Biol., 74, $11(1950)$.

s Groschke, A. C., and Evans, R. J., Poult. Sci., 29, 616 (1950).

- Coates, M. E., Dickinson, C. D., Harrison, G. F., Kon, S. K., and Mann, M. E., Proc. JX World's Poultry Congress, 2, 101 (1952).

\section{Ethylene Oxide for Soil Sterilization}

ETHYLENE oxide has been used for soil sterilization by introducing it under reduced pressure to containers holding the soil in pots or trays. Results have been satisfactory so far as sterilization is concerned, and there appears to be a minimum change in chemical and physical properties of the soil, though certain changes have been reported ${ }^{1}$.

Where a large number of pots has to be treated, this method may be time-consuming, and in view of the physical properties of ethylene oxide (solubility in water and boiling point $12 \cdot 5^{\circ} \mathrm{C}$.) it was considered that a more speedy method could be developed.

Fissentially the method consists of making up an aqueous solution to supply 2 or 4 c.c. of ethylene oxide in a given amount of water, using pre-chilled glassware and water. The container holding the soil is then watered with the solution and covered. In this trial, 1-lb. honey cartons were used (dimensions: base 2.5 in., height 4.0 in., top $3.5 \mathrm{in.})$ containing about $400 \mathrm{gm}$. of soil, and 100 c.c. of 2 and 4 per cent solutions of ethylene oxide applied. The containers rested in a Petri plate bottom and were covered with a top. A fair seal was formed in this manner, and if necessary could be improved by the use of a little petroleum jelly around the edge of the pot.

Amounts of water used must be found by trial beforehand according to the initial moisture status of the soil. The soil used in these experiments was a light sandy loam sieved through a $\frac{1}{4}$-in. mesh and thoroughly mixed.

The following methods were used and replicated five times, a bulked sample being used for microfloral counts: (1) control; (2) 100 c.c. of 2 per cent ethylene oxide watered on chilled soil and returned to the refrigerator for $12 \mathrm{hr}$.; (3) 100 c.c. of 4 per cent ethylene oxide watered on chilled soil and returned to the refrigerator for $12 \mathrm{hr}$.; (4) 100 c.c. of 2 per cent ethylene oxide watered on to soil at room temperature and left for $12 \mathrm{hr}$.; (5) autoclaved at $15 \mathrm{lb}$. for $20 \mathrm{~min}$.: (6) sterilized in an electric sterilizer (10 kilos of soil were put in a box with a tight-fitting lid with aluminium electrodes 14 in. $\times 10$ in. separated by $5 \frac{1}{2}$ in. This was operated from a $230-V$. A.c. current supply. The soil was moistened and after three hours the temperature had reached $95^{\circ} \mathrm{C}$, , when the sample was taken).

For testing purposes $10 \mathrm{gm}$. of soil was taken and diluted to $1 / 20,000$ for fungal counts and $1 / 100,000$ for bacterial and actinomyces counts, three parallel plates being used for each count. Some results are printed in the accompanying table.

\begin{tabular}{|l|c|c|c|}
\hline \multicolumn{1}{|c|}{ Treatment } & $\begin{array}{c}\text { Fungi } \\
\text { (thousands) }\end{array}$ & $\begin{array}{c}\text { Bacteria } \\
\text { (millions) }\end{array}$ & $\begin{array}{c}\text { Actinomyces } \\
\text { (millions) }\end{array}$ \\
\hline 1. Control & 230 & $4 \cdot 3$ & $4 \cdot 7$ \\
2. 2 c.c. chilled soil & 13 & $1 \cdot 8$ & $1 \cdot 8$ \\
3. 4 c.c. chilled soil & 0 & $0 \cdot 1$ & $0 \cdot 2$ \\
4. 2 c.c. room temp. soil & 0 & $0 \cdot 3$ & $0 \cdot 2$ \\
5. Autoclaved & 13 & $0 \cdot 0$ & $0 \cdot 03$ \\
6. Tilectric sterilizer & $0 \cdot 0$ & $0 \cdot 0$ & $0 \cdot 0$ \\
\hline
\end{tabular}

It would appear, therefore, that for experiments involving soil inoculation work, this modified method (treatment No. 4 in particular) has the merits of speed and simplicity and minimum changes in soil chemical and structural changes. A further study considering different amounts of ethylene oxide and initial soil temperatures appears warranted.

Treatments 5 and 6 should be highly effective from the point of view of sterilization, but probably result in more substantial physical and chemical changes. The figure of 13,000 fungi in the case of treatment 5 appears high and may be due to contamination.

Trials using these soils are in progress and will be reported on at a later date.
R. E. Rose
R. W. BAILEY

Rukuhia Soil Research Station

(Department of Agriculture), Hamilton,

New Zealand.

Nov. 20.

Clarke, F. E., Soil Sci., 345 (Nov, 1950). 